\title{
Primary sternum diffuse large B-cell lymphoma: A case report and review of the literature
}

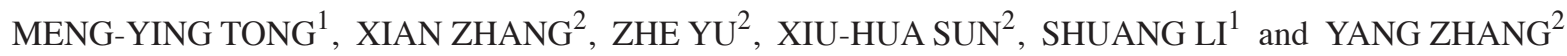 \\ ${ }^{1}$ Graduate Institute of Dalian Medical University, Dalian, Liaoning 116044; ${ }^{2}$ Department of Oncology, \\ The Second Affiliated Hospital of Dalian Medical University, Dalian, Liaoning 116027, P.R. China
}

Received June 7, 2014; Accepted February 25, 2015

DOI: $10.3892 / \mathrm{ol} .2015 .3122$

\begin{abstract}
Primary bone lymphoma (PBL) is a rare disease, accounting for $>1 \%$ of all cases of malignant lymphoma. Diffuse large B-cell lymphoma (DLBCL) is the most common histological type of PBL. The present study reported the case of a 68-year-old male with primary bone DLBCL, originally occurred in the sternum, which is a rare form of presentation. Computed tomography (CT), magnetic resonance imaging and bone emission CT were performed, followed by immunohistochemical analysis of a biopsy specimen, and the results were used to establish the diagnosis. At the time of diagnosis, no osseous involvement was observed. The clinical, radiological and histological features of PBL can mimic other medical conditions, thereby making the diagnosis difficult, and frequently leading to delays in treatment. The present study investigated the clinical features, management and prognosis of PBL, and reviewed previous relevant cases.
\end{abstract}

\section{Introduction}

Primary bone lymphoma (PBL) is an uncommon, malignant, neoplastic disorder of the skeleton, which accounts for $5-7 \%$ of primary bone tumors, $4-5 \%$ of extranodal non-Hodgkin lymphomas (NHLs) $(1,2)$ and $1 \%$ of all NHLs (3-5). Diffuse large B-cell lymphoma (DLBCL) is the most common histological type of PBL, and the majority of patients have limited-stage disease (stages IE-IIE) at presentation (4,6-9). The most common symptoms at presentation are pain, swelling and pathologic fractures (PFs), however, systemic symptoms, such as fever, night sweats and weight loss, occur less frequently in PBL when compared with other NHLs (10). Previous studies have reported the use of radiotherapy, chemotherapy or a

Correspondence to: Professor Yang Zhang, Department of Oncology, The Second Affiliated Hospital of Dalian Medical University, 467 ZhongShan Road, Dalian, Liaoning 116027, P.R. China

E-mail: 15040621011@163.com

Key words: primary bone lymphoma, sternum, diffuse large B-cell lymphoma combination of the two for the treatment of PBL, resulting in a generally good prognosis. The present study reported a case of PBL of the sternum and reviewed previous relevant cases, suggesting potential future investigations.

\section{Case report}

A 68-year-old male with a four-month history of a sternal mass was admitted to the Second Affiliated Hospital of Dalian Medical University (Dalian, China) in March 2014. The patient complained of bone swelling in the sternum, but did not present systemic symptoms, including fever, night sweats or weight loss. A physical examination detected an $8 \times 6-\mathrm{cm}$ painless, firm mass on the anterior sternum, a $4 x 1-\mathrm{cm}$ flat mass in the right side of the anterior inferior rib and an $1 \times 1-\mathrm{cm}$, enlarged cervical lymph node. Laboratory tests revealed increased serum levels of lactate dehydrogenase (LDH) (381 U/1; normal, 10-240 U/1) and erythrocyte sedimentation rate $(64 \mathrm{~mm} / \mathrm{h}$; normal, $0-15 \mathrm{~mm} / \mathrm{h})$. A computed tomography (CT) scan identified a soft tissue mass eroding the sternum, cortical breakthrough and a destructive osteolytic lesion in the sternum, which was permeative with a 'moth-eaten' appearance and an irregular margin. In addition, bone destruction in his right side of the anterior inferior rib was observed (Fig. 1). A magnetic resonance imaging (MRI) scan revealed a mass with a size of 34x63 mm arising from the sternum, which presented moderately long $\mathrm{T} 1$ and $\mathrm{T} 2$ signal intensities on a T1-weighted image (WI) and T2-WI, respectively, with involvement of the surrounding soft tissue (Fig. 2). Furthermore, a bone emission CT (ECT) scan demonstrated increased tracer uptake in the two humeri, right clavicle, spine, right femur and left tibia, which demonstrated multiple bone metastases (Fig. 3). A bone marrow cytology examination was normal.

Initially, the patient was considered to suffer from a bone tumor due to the presence of a soft tissue mass eroding the bone, as determined using imaging. However, PBL was also considered as a differential diagnosis. Establishing a diagnosis was challenging and pathological results were required for verification. A superficial temporal artery biopsy revealed a diagnosis of DLBCL, not otherwise specified (NOS), germinal center B-cell-like (GCB; Fig. 4). Immunohistochemical staining demonstrated that the biopsy specimen was positive for CD20, CD79a, B-cell lymphoma (BCL)-6, CD10, multiple myeloma oncogene 1 and epithelial membrane 
A

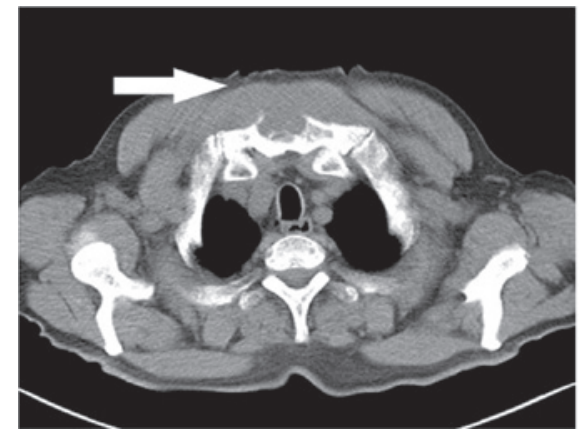

B

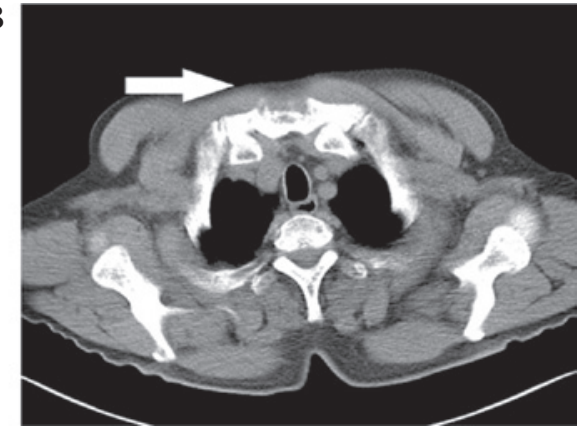

Figure 1. Computed tomography scans revealed bone destruction in the sternum. Images (A) prior to and (B) following treatment.

A

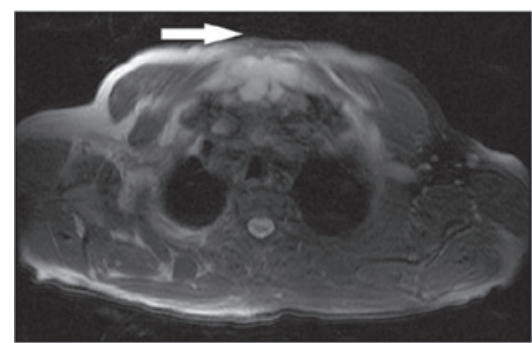

C

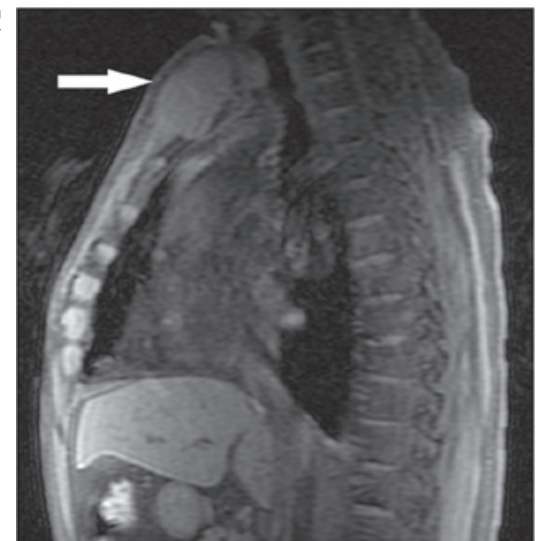

B

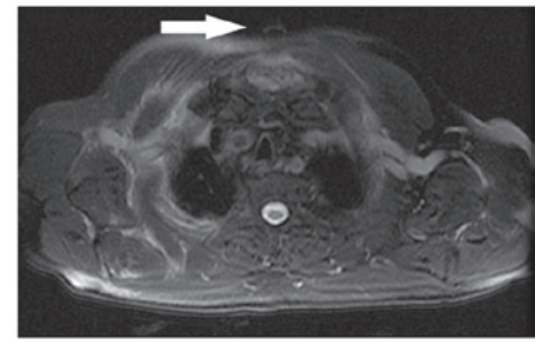

D

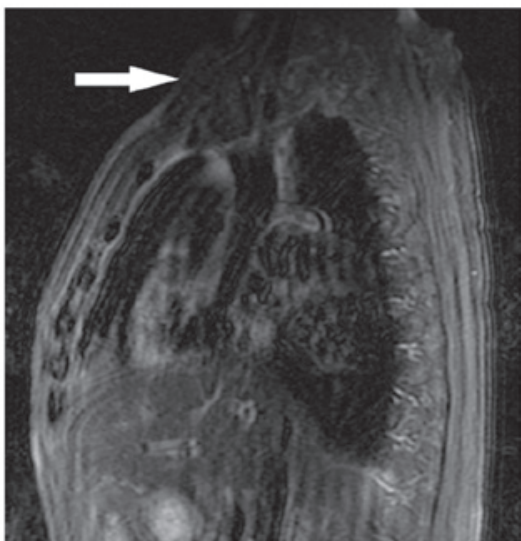

Figure 2. Magnetic resonance imaging scan revealed a soft tissue mass eroding the sternum. The images demonstrate the transversal view (A) prior to and (B) following treatment, and the sagittal view (C) prior to and (D) following treatment.

antigen, revealing a high proliferative index $(\mathrm{Ki}-67=70 \%)$. However, the specimen was negative for CD5, CD3, anaplastic lymphoma kinase, CD30, BCL-2 and anion exchanger (AE)1/AE3 (Fig. 4). These results led to the diagnosis of DLBCL (NOS, GCB), stage IVA (Ann Arbor staging system) (6), with an international prognostic index (IPI) (11) score of 4, which indicated that the patient belonged to the high-risk group. The five-year overall survival (OS) of the high-risk group is $26 \%$, indicating a poor prognosis (11).

Based on the results of the present case, diagnosis of PLB using imaging is difficult, since the findings are not pathognomonic, and a prompt histological examination may define the diagnosis and avoid the delay in treatment. The patient of the current study was treated with the cyclophosphamide, epirubicin, vincristine and prednisone (CHOP) regimen, with the absence of rituximab due to its high cost. Epirubicin was used in place of doxorubicin, as they are the same type of chemotherapeutic agent and have a similar mechanism of action. The patient completed four chemotherapy cycles: Cyclophosphamide, $750 \mathrm{mg} / \mathrm{m}^{2}$ iv d1; epirubicin, $50 \mathrm{mg} / \mathrm{m}^{2}$ iv

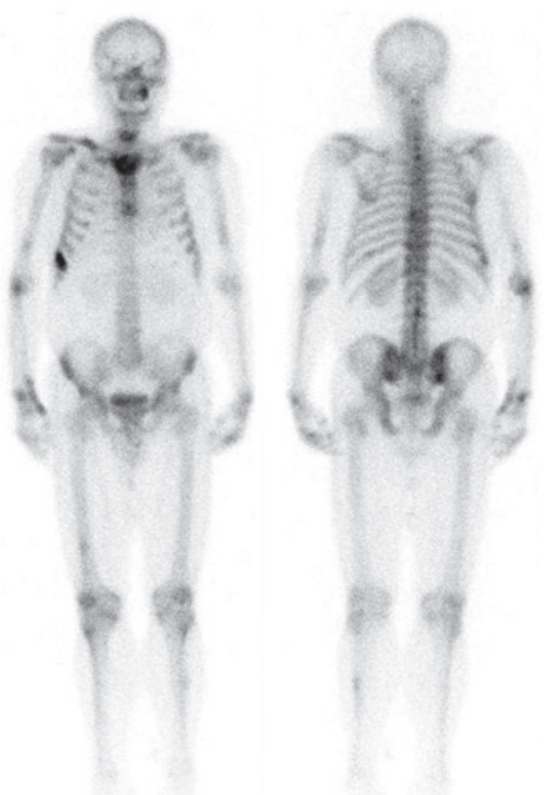

Figure 3. Emission computed tomograph revealed multiple bone metastases. 


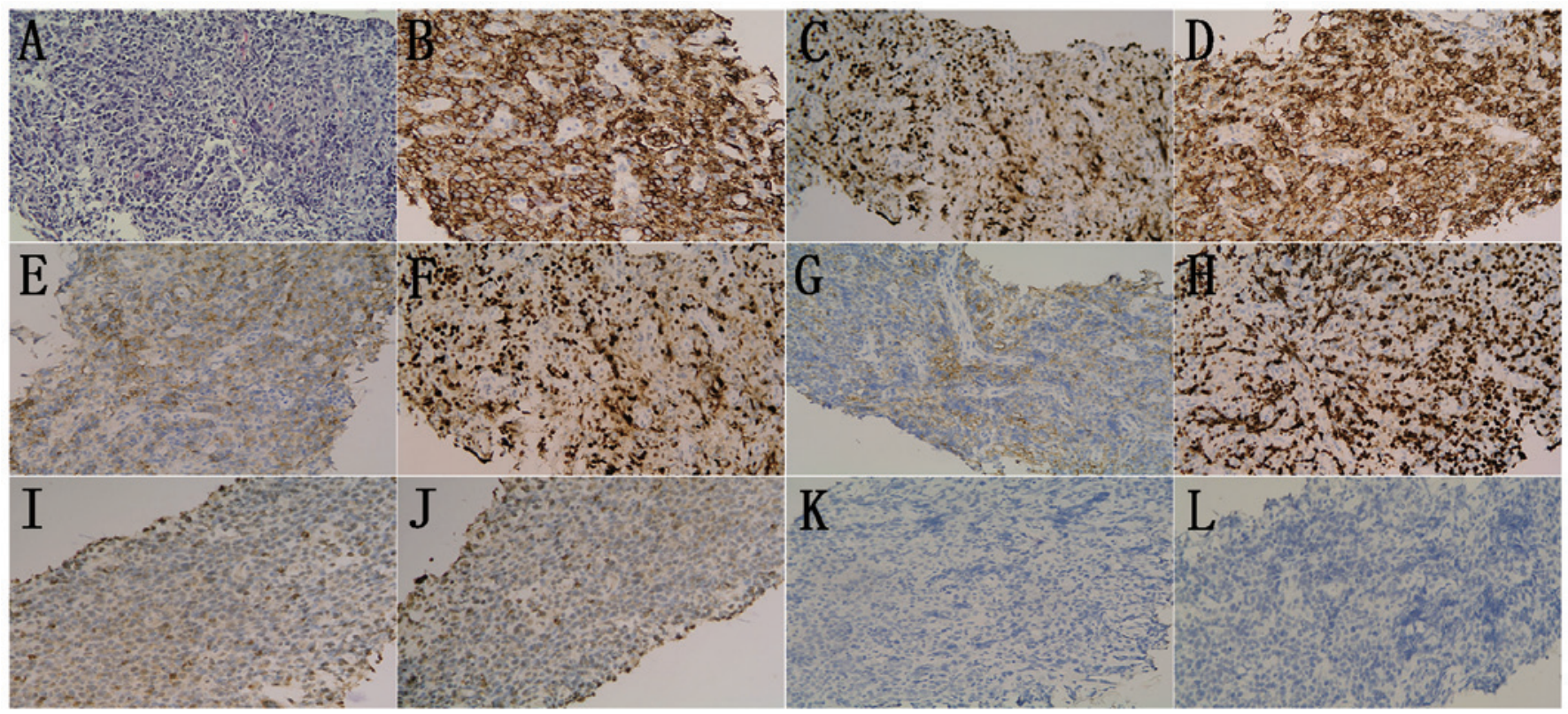

Figure 4. Diffuse infiltration of large B-cells. (A) Hematoxylin and eosin stained cells. Immunohistochemical analysis revealed that the samples were positive for (B) CD20, (C) CD79a, (D) BCL-6, (E) CD10, (F) MUM-1, partially positive for (G) EMA and (H) Ki-67 index 70\%; and negative for (I) CD5, (J) CD3, (K) BCL-2 and (L) AE1/AE3. (hematoxylin and eosin staining; magnification, x200). MUM-1, multiple myeloma oncogene 1; EMA, epithelial membrane antigen; Bcl, B-cell lymphoma; AE, anion exchanger.

d1; vincristine, $1.4 \mathrm{mg} / \mathrm{m}^{2}$ iv d1; prednisone, $100 \mathrm{mg} / \mathrm{m}^{2}$ po d1-5, 21 day per cycle, and the response evaluation indicated partial remission according to Cheson's criteria (12), with evidence of rapid reduction of all the lesions. The size of the sternal mass decreased to $2 \times 1 \mathrm{~cm}$, while the mass on the right side of the anterior inferior rib disappeared (Figs. 1 and 2). The patient completed eight chemotherapy cycles; the last followup was December 2014 and response evaluation indicated almost complete remission. At present, the patient remains in follow-up, and the development of the disease will continue to be monitored. Written informed consent was obtained from the patient prior to the publication of the present study. The study was approved by the ethics committee of The Second Affiliated Hospital of Dalian Medical University, Dalian, China.

\section{Discussion}

The most common sites of involvement in PBL are the extremities. For instance, Beal et al reported that the femur (27\%), pelvis (15\%) and tibia/fibula (13\%) are the three commonly-affected locations (10). A case with initial involvement of the sternum was described in the present study, which is an uncommon phenotype in PBL. To the best of our knowledge, only six such cases have been previously reported in the medical literature (13-18). In addition, the clinical characteristics are nonspecific, making the diagnosis difficult at the onset.

PBL commonly affects male individuals with an age range between mid-40 and mid-60 years. The most common presentations are pain, swelling and PFs, while systemic symptoms, including fever, night sweats and weight loss, occur less frequently in PBL compared with other non-Hodgkin lymphomas (NHLs) (10). The majority of patients in previous studies presented with localized disease (19-21); however, with the improvements in imaging techniques, including CT, MRI, ECT and ${ }^{18} \mathrm{~F}$-fluorodeoxyglucose-positron emission tomography (PET)/CT, the incidence of multifocal disease has increased (22). MRI is more accurate in evaluating PBL, which is particularly useful in evaluating the extent of soft tissue extension, spine involvement and spinal cord compression, as well as assisting the reduction of the volume irradiated (3). In addition, a previous study suggested that PET/CT is more accurate compared with bone ECT in assessing bone involvement by lymphoma (23). In addition, PET/CT has been demonstrated to be superior to CT and MRI, particularly in multifocal disease, and may be significant in the assessment of response to treatment (24). However, the imaging characteristics of PBL are variable, with detectable abnormalities, and nonspecific to the diagnosis for PBL. Therefore, adequate biopsy for histological examination and immunophenotyping remains the gold standard for diagnosis. In the present case, specific markers were selected, as immunohistochemically, DLBCL is often observed to be positive for CD10, CD20 and CD79a, while it is frequently negative for CD3, CD5, CD43, AE1/AE3 and BCL-2. Furthermore, BCL-6 and MUM-1 are used to distinguish between GCB and non-GCB types.

The diagnosis of PBL presents a variety of challenges and, due to the absence of prospective clinical studies, the majority of PBLs are treated with chemotherapy and/or radiotherapy. Radiotherapy was established as the standard treatment in earlier years $(19,20)$. However, with the development of highly effective chemotherapy regimens and particularly the advent of novel agents, such as the anti-CD20 monoclonal antibody rituximab, the role of radiotherapy has been increasingly questioned by certain researchers $(2,25-27)$. Considering current studies and several previously-published studies, patients treated with chemoradiotherapy appeared to present an improved outcome compared with patients receiving single 
Table I. Representative series describing patients with PBL.

\begin{tabular}{lcccccccc}
\hline $\begin{array}{l}\text { Study } \\
\text { period }\end{array}$ & Number & $\begin{array}{c}\text { Stage I } \\
\text { and II }(\%)\end{array}$ & Stage IV $(\%)$ & CXT only $(\%)$ & RT only $(\%)$ & CXRT $(\%)$ & $\begin{array}{c}\text { Five-year } \\
\text { OS rate }(\%)\end{array}$ & Reference \\
\hline $1907-1982$ & 422 & 62 & 38 & 8 & 57 & 24 & NA & $(46)$ \\
$1943-1996$ & 60 & 62 & 16 & NA & 8 & 58 & 61 & $(47)$ \\
$1961-1999$ & 94 & 74 & 26 & 7 & 3 & 53 & 88 & $(48)$ \\
$1963-2003$ & 82 & 81 & 0 & 30 & 13 & 57 & 88 & $(27)$ \\
$1967-1992$ & 45 & 100 & 0 & 8 & 11 & 80 & 68 & $(20)$ \\
$1970-1978$ & 37 & 100 & 0 & 5 & 0 & 95 & 91 & $(21)$ \\
$1970-2003$ & 37 & 100 & 0 & 46 & 41 & 8 & 65 & $(49)$ \\
$1973-2005$ & 1500 & 69 & 31 & NA & 68 & NA & 58 & $(50)$ \\
$1979-2007$ & 19 & 58 & 42 & 58 & 0 & 42 & NA & $(51)$ \\
$1980-2003$ & 100 & 0 & 100 & 36 & 0 & 64 & NA & $(36)$ \\
$1980-2005$ & 295 & 59 & 41 & 21 & 8 & 71 & 54 & $(52)$ \\
$1980-2005$ & 161 & 100 & 0 & 8 & 14 & 78 & 75 & $(34)$ \\
$1982-1998$ & 52 & 60 & 40 & 15 & 21 & 63 & 68 & $(30)$ \\
$1983-2001$ & 77 & 100 & 0 & NA & 13 & 87 & 88 & $(29)$ \\
$1983-2005$ & 131 & 46 & 54 & 44 & NA & 48 & 62 & $(23)$ \\
$1985-2003$ & 22 & 77 & 23 & NA & NA & 68 & 85 & $(37)$ \\
$1987-2008$ & 116 & 100 & 0 & 12 & 13 & 75 & 76 & $(28)$ \\
$1989-2005$ & 30 & 70 & 30 & 17 & 10 & 70 & 73 & $(31)$ \\
$1992-2010$ & 33 & 39 & 61 & 52 & 0 & 48 & 75 & $(53)$ \\
$1992-2012$ & 22 & 86 & 14 & 23 & 4 & 73 & 86 & $(54)$ \\
$1995-2004$ & 28 & 32 & 68 & NA & NA & 50 & 84 & $(55)$ \\
$1999-2009$ & 21 & 9 & 91 & 48 & 0 & 52 & 95 & $(33)$ \\
$1999-2011$ & 21 & 62 & 38 & 19 & 0 & 81 & 74 & $(44)$ \\
$2000-2007$ & 53 & 77 & 23 & 21 & 12 & 62 & 100 & $(32)$ \\
$2000-2011$ & 24 & 67 & 33 & 62 & 0 & 38 & 67 & $(56)$ \\
NA & 28 & 100 & 0 & 0 & 32 & 68 & 60 & $(57)$ \\
NA & 31 & 68 & 32 & 0 & 0 & 100 & 90 & $(58)$ \\
\hline
\end{tabular}

CXT, chemotherapy; RT, radiotherapy; CXRT, chemoradiotherapy; OS, overall survival; NA, not available.

modality therapy (25-29). These observations require confirmation by prospective studies with larger sample groups, since specific studies appear to disprove them $(2,26,27,33,34)$. For instance, in the IELSG-14 study, the addition of radiotherapy following chemotherapy, or the use of larger radiation fields and doses, were not associated with an improved outcome in patients treated with chemoradiotherapy (9). Although previous studies have obtained contradicting results, chemoradiotherapy is likely to be superior to single modality therapy, which may be advantageous for localized unifocal bulky sites of disease, which allows a shorter chemotherapy course $(1,30,35)$, or for multifocal disease in relapsing cases (36). Anthracycline-containing chemotherapy has become the standard therapy of DLBCL, while numerous studies have demonstrated increased long term remission rates with the incorporation of rituximab (33,37-42). Based on the aforementioned findings, chemotherapy plus rituximab (immunochemotherapy) is currently considered to be the first-line treatment for CD20-positive DLBCLs. Furthermore, a number of studies pointed out that the positive effect of administering rituximab may be evident in certain subgroups of DLBCLs. For instance, previous results support that only BCL-2-positive $(43,44)$ or BCL-6-negative $(45)$ patients significantly benefited from rituximab. In addition, patients with activated B-cell-like-DLBCL appear to benefit more compared with GCB-DLBCL patients (45). Considering these observations, the patient of the present study may not benefit sufficiently from rituximab treatment.

Table I lists a number of representative studies reported in the English literature identified by searching PubMed and Mediline databases with the key words 'primary bone lymphoma' (1,2,9,19-21,27-34,47-59), which investigated the response of patients to chemotherapy and radiotherapy, regardless of the effect of surgery and molecular targeted therapy. From these studies (1,2,9,19-21,27-34,47-59), certain observations can be summarized and emphasized. First, an increasing number of patients are diagnosed with progressive stage PBL (patients were staged according to the Ann Arbor Staging System), due to the improvement in examination techniques. In addition, with the increase in the diagnostic rate of multifocal disease that is no longer suitable for radiotherapy and with the development of novel chemotherapy 
regimens, chemotherapy has gradually become the main treatment method. Furthermore, local stage was associated with the use of radiotherapy and advanced stage was significantly associated with chemotherapy. Therefore, the survival analysis of PBL patients revealed that chemoradiotherapy was associated with improved survival of local stage in previous studies $(21,28,31,49)$; however, no difference in the survival rates was observed compared with chemotherapy of advanced stage patients in recent studies $(2,9,54)$. Finally, the transformation of treatment mode was inevitable, which depends on the stage.

No conclusive view exists on the response of PBL to various radiotherapy doses, while the majority of studies used doses that are commonly used to treat NHL (35-45 Gy in 1.8-2 Gy fractions) $(1,30,31)$. However, a randomized trial conducted in the British population revealed that radiotherapy at a dose of $30 \mathrm{~Gy}$ following chemotherapy was adequate for the treatment of NHL, including extra-nodal sites (60), while higher doses may be reserved for cases with a suboptimal response to chemotherapy. Another issue is to determine whether surgery is required. At present, due to the development of effective oncological treatments, surgery is not routinely used in the management of PBL, with the exception of the initial biopsy performed to establish a diagnosis and the treatment of PFs $(1,22)$. A recent study reported that, although PFs occurred, the initial surgical stabilization of the PFs did not change the therapeutic outcome, and patients receiving chemotherapy prior to irradiation of the fractured bone exhibited an improved outcome (53).

The prognosis of PBL is relatively good and equal to that of same-stage systemic DLBCL (55). The five-year OS rates vary greatly, as demonstrated in clinical trials and retrospective population-based studies $(2,9,20,28,29,51,53)$. In addition, various studies have suggested different prognostic factors, including age $(29,50,51,56)$, gender (10), stage (2), LDH levels $(10)$, lesion range $(51)$ and IPI score $(28,56)$. Considering these factors, the case reported in the present study may have a poor prognosis. Notably, several recent studies confirmed that the only positive prognostic factor was complete remission (CR) following chemotherapy. Once a CR is achieved, even elderly patients may exhibit long-term survival, possibly obviating the requirement for surgery for less severe bone lesions $(57,61)$.

In conclusion, the case described in the current study improved the understanding on the characteristics of PBL. The present authors recommend that unusual and rare conditions should be considered as a differential diagnosis when dealing with bone tumors and highlight the paramount importance of histological analysis for a clarified diagnosis. Although the currently available data support the use of chemoradiotherapy for the treatment of PBL, further randomized controlled trials are required to evaluate the efficacy of this treatment strategy.

\section{References}

1. Ford DR, Wilson D, Sothi S, Grimer R and Spooner D: Primary bone lymphoma - treatment and outcome. Clin Oncol (R Coll Radiol) 19: 50-55, 2007.

2. Ramadan KM, Shenkier T, Sehn LH, Gascoyne RD and Connors JM: A clinicopathological retrospective study of 131 patients with primary bone lymphoma: a population-based study of successively treated cohorts from the British Columbia Cancer Agency. Ann Oncol 18: 129-135, 2007.
3. Krishnan A, Shirkhoda A, Tehranzadeh J, et al: Primary bone lymphoma: Radiographic-MR imaging correlation. Radiographics 23: 1371-1387, discussion 1384-1387, 2003.

4. Mengiardi B, Honegger H, Hodler J, et al: Primary lymphoma of bone: MRI and CT characteristics during and after successful treatment. Am J Roentgenol 184: 185-192, 2005.

5. Glotzbecker MP, Kersun LS, Choi JK, et al: Primary non-Hodgkin's lymphoma of bone in children. J Bone Joint Surg Am 88: 583-594, 2006.

6. Lister TA, Crowther D, Sutcliffe SB, et al: Report of a committee convened to discuss the evaluation and staging of patients with Hodgkin's disease: Cotswolds meeting. J Clin Oncol 7: 16301636, 1989

7. Reddy N and Greer JP: Primary bone lymphoma: A set of unique problems in management. Leuk Lymphoma 51: 1-2, 2010.

8. Zhao XF, Young KH, Frank D, et al: Pediatric primary bone lymphoma - diffuse large B-cell lymphoma: Morphologic and immunohistochemical characteristics of 10 cases. Am J Clin Pathol 127: 47-54, 2007.

9. Bruno Ventre M, Ferreri AJ, Gospodarowicz M, et al; International Extranodal Lymphoma Study Group: Clinical features, management, and prognosis of an international series of 161 patients with limited-stage diffuse large B-cell lymphoma of the bone (the IELSG-14 study). Oncologist 19: 291-298, 2014.

10. Beal K, Allen L and Yahalom J: Primary bone lymphoma: treatment results and prognostic factors with long-term follow-up of 82 patients. Cancer 106: 2652-2656, 2006.

11. No authors listed: A predictive model for aggressive non-Hodgkin's lymphoma. The International Non-Hodgkin's Lymphoma Prognostic Factors Project. N Engl J Med 329: 987-994, 1993.

12. Cheson BD, Horning SJ, Coiffier B, et al: Report of an international workshop to standardize response criteria for nonHodgkin's lymphoma. NCI Sponsored International Working Group. J Clin Oncol 17: 1244, 1999.

13. Langley CR, Garrett SJ, Urand J, Kohler J and Clarke NM: Primary multifocal osseous Hodgkin's lymphoma. World J Surg Oncol 6: 34, 2008.

14. Gupta A, Kataria SP, Kumar K and Subramanian S: Primary non Hodgkin's lymphoma of sternum. Indian J Med Paediatr Oncol 27: 28, 2006.

15. Levitt LJ, Aisenberg AC,Harris NL, et al: Primary non-Hodgkin's lymphoma of the mediastinum. Cancer 50: 2486-2492, 1982.

16. Kabiri el H, Kabiri M and Doghmi K: Primary non-Hodgkin lymphoma of the sternum. Arch Bronconeumol 45: 259-260, 2009 (In Spanish).

17. Maslovsky I and Gefel D: Hodgkin's disease. Haematologica 90 (12 Suppl): EIM02, 2005.

18. Graziadio M, Medina N, Amato M, et al: Primary bone lymphoma with multicentric involvement. Medicina (B Aires) 72: 428-430, 2012 (In Spanish).

19. Heyning FH, Hogendoorn PC, Kramer MH, et al: Primary non-Hodgkin's lymphoma of bone: a clinicopathological investigation of 60 cases. Leukemia 13: 2094-2098, 1999.

20. Demircay E, Hornicek FJ Jr, Mankin HJ and Degroot H III: Malignant lymphoma of bone: a review of 119 patients. Clin Orthop Relat Res 471: 2684-2690, 2013.

21. Dubey P, Ha CS, Besa PC, et al: Localized primary malignant lymphoma of bone. Int J Radiat Oncol Biol Phys 37: 1087-1093, 1997.

22. Mikhaeel NG: Primary bone lymphoma. Clin Oncol (R Coll Radiol) 24: 366-370, 2012.

23. Moog F, Kotzerke J and Reske SN: FDG PET can replace bone scintigraphy in primary staging of malignant lymphoma. J Nucl Med 40: 1407-1413, 1999.

24. Park YH, Kim S, Choi SJ, et al: Clinical impact of whole-body FDG-PET for evaluation of response and therapeutic decision-making of primary lymphoma of bone. Ann Oncol 16: $1401-1402,2005$.

25. Ng AK and Mauch PM: Role of radiation therapy in localized aggressive lymphoma. J Clin Oncol 25: 757-759, 2007.

26. Bonnet C, Fillet G, Mounier N, et al; Groupe d'Etude des Lymphomes de l'Adulte: CHOP alone compared with CHOP plus radiotherapy for localized aggressive lymphoma in elderly patients: A study by the Groupe d'Etude des Lymphomes de l'Adulte. J Clin Oncol 25: 787-792, 2007.

27. Reyes F, Lepage E, Ganem G, et al; Groupe d'Etude des Lymphomes de l'Adulte (GELA): ACVBP versus CHOP plus radiotherapy for localized aggressive lymphoma. N Engl J Med 352: 1197-1205, 2005. 
28. Beal K, Allen L and Yahalom J: Excellent long-term experience with primary bone lymphoma: Analysis of prognostic factors. J Clin Oncol 22: 6587, 2004.

29. Cai L, Stauder MC, Zhang YJ, et al: Early-stage primary bone lymphoma: a retrospective, multicenter rare cancer network (RCN) study. Int J Radiat Oncol Biol Phys 83: 284-291, 2012.

30. Barbieri E, Cammelli S, Mauro F, et al: Primary non-Hodgkin's lymphoma of the bone: treatment and analysis of prognostic factors for Stage I and Stage II. Int J Radiat Oncol Biol Phys 59. 760-764, 2004

31. Zinzani PL, Carrillo G, Ascani S, et al: Primary bone lymphoma: experience with 52 patients. Haematologica 88: 280-285, 2003.

32. Catlett JP, Williams SA, O'Connor SC, Krishnan J and Malkovska V: Primary lymphoma of bone: an institutional experience. Leuk Lymphoma 49: 2125-2132, 2008.

33. Alencar A, Pitcher D, Byrne G and Lossos IS: Primary bone lymphoma - the university of miami experience. Leuk Lymphoma 51: 39-49, 2010.

34. Pellegrini C, Gandolfi L, Quirini F, et al: Primary bone lymphoma: evaluation of chemoimmunotherapy as front-line treatment in 21 patients. Clin Lymphoma Myeloma Leuk 11: $321-325,2011$.

35. Horning SJ, Weller E, Kim K, et al: Chemotherapy with or without radiotherapy in limited-stage diffuse aggressive non-Hodgkin's lymphoma: Eastern cooperative oncology group study 1484. J Clin Oncol 22: 3032-3038, 2004.

36. Messina C, Ferreri AJ, Govi S, et al; International Extranodal Lymphoma Study Group (I.E.L.S.G.): Clinical features, management and prognosis of multifocal primary bone lymphoma: a retrospective study of the international extranodal lymphoma study group (the IELSG 14 study). Br J Haematol 164 834-840, 2014.

37. Gutiérrez-García G, Colomo L, Villamor N, et al: Clinico-biological characterization and outcome of primary noda and extranodal diffuse large B-cell lymphoma in the rituximab era. Leuk Lymphoma 51: 1225-1232, 2010.

38. Rieger M, Osterborg A, Pettengell R, et al; MabThera International Trial (MInT) Group: Primary mediastinal B-cell lymphoma treated with CHOP-like chemotherapy with or without rituximab: results of the Mabthera International Tria Group study. Ann Oncol 22: 664-670, 2011.

39. Feugier P, Van Hoof A, Sebban C, et al: Long-term results of the R-CHOP study in the treatment of elderly patients with diffuse large B-cell lymphoma: a study by the Groupe d'Etude des Lymphomes de l'Adulte. J Clin Oncol 23: 4117-4126, 2005.

40. Pfreundschuh M, Trümper L, Osterborg A, et al; MabThera International Trial Group: CHOP-like chemotherapy plus rituximab versus CHOP-like chemotherapy alone in young patients with good-prognosis diffuse large-B-cell lymphoma: a randomised controlled trial by the MabThera international tria (MInT) group. Lancet Oncol 7: 379-391, 2006.

41. Sehn LH, Donaldson J, Chhanabhai M, et al: Introduction of combined CHOP plus rituximab therapy dramatically improved outcome of diffuse large B-cell lymphoma in British Columbia. $\mathrm{J}$ Clin Oncol 23: 5027-5033, 2005.

42. Qian L, Zhang Z, Shen J and Liu Y: Primary bone marrow B-cell non-Hodgkin's lymphoma successfully treated with R-CHOP. West Indian Med J 62: 89-91, 2013.

43. Shivakumar L and Armitage JO: Bcl-2 gene expression as a predictor of outcome in diffuse large B-cell lymphoma. Clin Lymphoma Myeloma 6: 455-457, 2006.
44. Mounier N, Briere J, Gisselbrecht C, et al; Groupe d'Etude des Lymphomes de l'Adulte: Estimating the impact of rituximab on bcl-2-associated resistance to CHOP in elderly patients with diffuse large B-cell lymphoma. Haematologica 91: 715-716, 2006.

45. Winter JN, Weller EA, Horning SJ, et al: Prognostic significance of Bcl-6 protein expression in DLBCL treated with CHOP or R-CHOP: a prospective correlative study. Blood 107: 4207-4213, 2006

46. Nyman H, Adde M, Karjalainen-Lindsberg ML, et al: Prognostic impact of immunohistochemically defined germinal center phenotype in diffuse large B-cell lymphoma patients treated with immunochemotherapy. Blood 109: 4930-4935, 2007.

47. Rigacci L, Scoccianti G, Puccini B, et al: Primary lymphoma of bone: single center experience. Drugs Cell Ther Hematol 2: 147-156, 2013.

48. Ostrowski ML, Unni KK, Banks PM, et al: Malignant lymphoma of bone. Cancer 58: 2646-2655, 1986.

49. Fidias P, Spiro I, Sobczak ML, et al: Long-term results of combined modality therapy in primary bone lymphomas. Int J Radiat Oncol Biol Phys 45: 1213-1218, 1999.

50. Horsman JM, Thomas J, Hough R and Hancock BW: Primary bone lymphoma: a retrospective analysis. Int $\mathrm{J}$ Oncol 28: $1571-1575,2006$

51. Jawad MU, Schneiderbauer MM, Min ES, et al: Primary lymphoma of bone in adult patients. Cancer 116: 871-879, 2010.

52. Stein ME, Kuten A, Gez E, et al: Primary lymphoma of bone - a retrospective study. Experience at the Northern Israel Oncology Center (1979-2000). Oncology 64: 322-327, 2003.

53. Govi S, Christie D, Messina C, et al; International Extranodal Lymphoma Study Group (I.E.L.S.G.): The clinical features, management and prognostic effects of pathological fractures in a multicenter series of 373 patients with diffuse large B-cell lymphoma of the bone. Ann Oncol 25: 176-181, 2014.

54. Kim SY, Shin DY, Lee SS, et al: Clinical characteristics and outcomes of primary bone lymphoma in Korea. Korean J Hematol 47: 213-218, 2012.

55. Matikas A, Briasoulis A, Tzannou I, et al: Primary bone lymphoma: a retrospective analysis of 22 patients treated in a single tertiary center. Acta Haematol 130: 291-296, 2013.

56. Maruyama D, Watanabe T, Beppu Y, et al: Primary bone lymphoma: a new and detailed characterization of 28 patients in a single-institution study. Jpn J Clin Oncol 37: 216-223, 2007.

57. Liu YC, Gau JP, Yu YB, et al: Prognostic factors and treatment efficacy in patients with primary diffuse large B-cell lymphoma of the bone: single institute experience over 11 years. Intern Med 53: 95-101, 2014.

58. Marshall DT, Amdur RJ, Scarborough MT, et al: Stage IE primary non-Hodgkin's lymphoma of bone. Clin Orthop Relat Marshall Res 405: 216-222, 2002.

59. Christie D, Dear K, Le T, et al: Limited chemotherapy and shrinking field radiotherapy for osteolymphoma (primary bone lymphoma): results from the trans-Tasman Radiation Oncology Group 99.04 and Australasian Leukaemia and Lymphoma Group LY02 prospective trial. Int J Radiat Oncol Biol Phys 80: 1164-1170, 2011.

60. Lowry L, Smith P, Qian W, et al: Reduced dose radiotherapy for local control in non-Hodgkin lymphoma: a randomised phase III trial. Radiother Oncol 100: 86-92, 2011.

61. Scoccianti G, Rigacci L, Puccini B, et al: Primary lymphoma of bone: outcome and role of surgery. Int Orthop 37: 2437-2442, 2013. 